\title{
Qualidade e avaliação externa: relações estabelecidas por Orientadores Pedagógicos e Professores de quatro escolas da Rede Municipal de Ensino de Campinas
}

\author{
Quality and External Evaluations: relations established by Pedagogical Advisors and Teachers from \\ four schools of the Municipal Education Network of Campinas \\ Qualité et évaluation externe: relations établies par les Conseillers Pédagogiques et les Enseignants de \\ quatre écoles du Réseau Municipal d'éducation de Campinas
}

Luana Ferrarotto ${ }^{1}$ Instituto Federal de Educação, Ciência e Tecnologia de São Paulo

Resumo: O artigo discute a relação entre qualidade e avaliação externa em larga escala a partir das vozes de Orientadores Pedagógicos (OPs) e professores de quatro escolas da Rede Municipal de Ensino de Campinas (RMEC). Foram entrevistados OPs e docentes de escolas com diferentes cenários de enraizamento da política de Avaliação Institucional Participativa, existente na RMEC desde 2008. Percebe-se que para os entrevistados a qualidade do trabalho desenvolvido pela instituição não pode ser conhecida, integralmente, pelos resultados obtidos em avaliações externas. Embora algumas falas destaquem a importância da contextualização desses dados, não foi possível perceber, ainda, uma análise ampliada da qualidade da escola, na perspectiva da qualidade social.

Palavras-chave: Avaliação externa em larga escala. Avaliação institucional participativa. Escola pública. Qualidade.

Abstract: The article covers the relation between quality and large scale external evaluation based on the thoughts of Pedagogical Advisors (OPs) and teachers from four schools of the Municipal Education Network of Campinas (RMEC). It was interviewed OPs and teachers from schools with different rooting scenarios of the Participative Institutional Assessment, present in the RMEC since 2008. It can be noticed that for the interviewees, the quality of the work done by the institution can't be completely recognized by the results achieved in external evaluations. Even though some quotes highlight the importance of the contextualization of this data, it wasn't possible to see an expanded analysis of the quality of the school based on a social quality perspective.

Keywords: Large scale external evaluation. Participatory institutional evaluation. Public school. Quality.

Résumé: L'article examine la relation entre la qualité et l'évaluation externe à grande échelle basée sur les voix des conseillers pédagogiques (OP) et des enseignants de quatre écoles du réseau municipal d'éducation de Campinas (RMEC). Les OP et les enseignants ont été interrogés avec différents scénarios d'enracinement de la politique d'évaluation institutionnelle participative, qui existe au RMEC depuis 2008. On constate que pour les personnes interrogées, la qualité du travail développé par l'institution ne peut être pleinement connue pour les résultats obtenus en évaluations externes. Bien que certaines déclarations soulignent l'importance de

\footnotetext{
${ }^{1}$ Doutora em Educação. Professora no Instituto Federal de Educação, Ciência e Tecnologia de São Paulo, Campus Bragança Paulista. E-mail: luanaferrarotto@yahoo.com.br. Lattes: http://lattes.cnpq.br/2883094594167323. Orcid: https://orcid.org/0000-0002-2861-2127.
} 
contextualiser ces données, il n'a pas encore été possible de percevoir une analyse approfondie de la qualité de l'école, du point de vue de la qualité sociale.

Mots-clés: Évaluation externe à grande échelle. Évaluation institutionnelle participative. École publique, qualité.

Recebido em: 20 de maio de 2020 Aceito em: 17 de maio de 2020

\section{Considerações Iniciais}

Qualidade e avaliação são termos que frequentemente aparecem atrelados nos discursos que acompanham as políticas públicas educacionais. No entanto, qualidade não é um conceito entendido igualmente por diferentes atores sociais. Como afirmam Oliveira e Araújo (2005), Silva (2009) e Sousa (2014), trata-se de termo complexo e polissêmico. E, como destaca Cabrito (2009, p. 181), o modo como entendemos a qualidade condiciona a forma de “avaliar’ a sua concretização” (aspas do original).

No Brasil, sobretudo a partir da década de 1990, as avaliações externas em larga escala adentram as redes públicas de ensino como consequência do avanço neoliberal na condução das ações do Estado. As reformas empreendidas passaram a seguir o receituário dos organismos internacionais ${ }^{2}$ que, dentre outras recomendações, estabelece conteúdos mínimos de aprendizagem³, voltados à leitura, à escrita, ao cálculo e à resolução de problemas, entendidos como ingredientes fundamentais para o incremento da produtividade (LIBÂNEO, 2013). Nesse cenário, a instituição de sistemas de avaliação é incentivada pelo Banco Mundial a fim de monitorar os resultados obtidos a partir das ações realizadas. Assim, paulatinamente, temos a constituição do Sistema de Avaliação da Educação Básica (Saeb), cujo objetivo é "avaliar a educação básica brasileira e contribuir para a melhoria de sua qualidade [...] oferecendo subsídios concretos para a formulação, reformulação e o monitoramento das políticas públicas" (INEP, grifos nossos).

Vale lembrar que em 2005 ocorre a ampliação do Saeb, por meio da Avaliação Nacional do Rendimento Escolar (Anresc), conhecida como Prova Brasil que, juntamente com o fluxo escolar, é utilizada no cálculo do Índice de Desenvolvimento da Educação Básica (Ideb). Com a Prova Brasil e o Ideb, inicia-se um movimento de ampla divulgação de

\footnotetext{
${ }^{2}$ Robertson (2012, p. 283) menciona que a função dos organismos internacionais, sobretudo do Banco Mundial, é "lidar com os fracassos do neoliberalismo reinventando as mais avançadas rodadas de intervenção neoliberal". Nessa esteira, Pereira (2016) destaca que os organismos internacionais, em seus documentos, associam a educação às demandas do desenvolvimento econômico.

3 Recomendação presente no Plano Decenal para os países mais populosos do Terceiro Mundo, resultado da Conferência Mundial sobre Educação para Todos, realizada na Tailândia em 1990 e promovida pelo Banco Mundial.
} 
resultados que conduz à responsabilização das instituições e de seus atores (FREITAS, 2013). Há, portanto, um aprofundamento na lógica iniciada na década de 1990.

Na análise de Coelho (2008, p. 237), com a instituição dos sistemas de avaliação, o que se pretendia era "monitorar a qualidade" e "controlar o cumprimento do que foi estabelecido como metas". Desse modo, a avaliação se associa à qualidade, mais especificamente, às metas que foram projetadas para a educação. Metas que, considerando as características das avaliações externas em larga escala, vinculam-se aos índices quantificáveis obtidos com a aplicação periódica de testes padronizados.

Silva (2009, p. 220) ressalta que essa "avaliação quantitativista constituiu um dos instrumentos para adaptar o sistema educacional brasileiro à nova ordem global instituída nos anos de 1990”. Assim, presenciamos a transposição da concepção de qualidade do campo econômico para a educação, já que tal concepção passa a ser guiada por "parâmetros de utilidade, praticidade e comparabilidade, utilizando medidas e níveis mensuráveis, padrões, rankings, testes comparativos, hierarquização e estandardização próprias do âmbito mercantil” (SILVA, 2009, p. 219).

Por conseguinte, como já sinalizado por alguns estudos, há repercussões na organização do trabalho pedagógico, dentre as quais podemos destacar o treino para os testes padronizados e o ensino focalizado nas habilidades e competências previstas na matriz das avaliações externas (RAVITCH, 2013; SCHNEIDER, 2013; MENEGÃO, 2016). Desse modo, valoriza-se mais os resultados obtidos do que o processo, há mais destaque para a avaliação externa do que para a avaliação interna, contribuindo para a uniformização entre as escolas, em consonância com os padrões definidos pelos organismos internacionais (PACHECO, 2014).

Compreendendo que as ações decorrentes dos significados atribuídos à qualidade e avaliação "podem servir a propósitos de democratização, como podem potencializar iniciativas que intensifiquem desigualdades e levem à exclusão" (SOUSA; LOPES, 2010, p. 55), neste artigo discutiremos a relação entre qualidade e avaliação externa em larga escala a partir das vozes de Orientadores Pedagógicos (OP) e professores de quatro escolas municipais da Rede Municipal de Ensino de Campinas (RMEC).

Precisamos considerar que a referida rede de ensino iniciou, em 2008, a implementação da política de Avaliação Institucional Participativa (AIP) a fim de fortalecer os processos de autoavaliação das escolas municipais (RESOLUÇÃO 05/2008). Assim, cada escola deve compor uma Comissão Própria de Avaliação (CPA), com representantes dos diferentes 
segmentos da sua comunidade ${ }^{4}$, para organizar e estudar os diversos dados relacionados à instituição, com vistas a identificar potencialidades e fragilidades, bem como negociar ações.

$\mathrm{Na}$ AIP, espera-se que os processos avaliativos sejam guiados por uma concepção ampliada de qualidade que se aproxima da qualidade socialmente referenciada. Conforme explica Silva (2009), a qualidade social tem como foco a reflexão sobre o conjunto de dimensões socioeconômicas e culturais que circundam a comunidade escolar (aspectos externos), articulado às ações e projetos desenvolvidos pela instituição (aspectos internos), sem perder de vista a busca por condições adequadas de trabalho, de modo a promover aprendizagens significativas e democráticas para todos e todas. Por esse motivo, temos como interesse identificar se a relação entre qualidade e avaliação externa em larga escala, estabelecida por OPs e docentes de escolas da RMEC, aproxima-se da lógica da quantificação dos resultados, reduzindo as ações escolares a esses números ou se, na contramão, converge para um olhar mais amplo que, em nosso entendimento, deve reger os processos avaliativos por abarcar diversos fatores na análise dos dados obtidos, compreendendo a escola em sua multidimensionalidade.

\section{Percurso Metodológico}

Como anteriormente apresentamos, neste artigo discutiremos a relação entre qualidade e avaliação externa em larga escala a partir das vozes de OPs e professores de quatro escolas da RMEC. Para tanto, optamos por estabelecer contato com escolas com diferentes cenários indicativos de enraizamento da política de Avaliação Institucional Participativa, pois tínhamos como hipótese que em instituições com processos de AIP mais potencializados, encontraríamos um olhar mais ampliado para a qualidade escolar, em que os resultados das avaliações externas em larga escala fossem tomados como um dos indicadores analisados, sem ser o único e/ou o principal, articulando-os com aspectos internos e externos à escola.

Para a seleção das escolas, consideramos as indicações feitas, em entrevista, pelos quatro membros da Assessoria de $\mathrm{AIP}^{5}$, atuantes entre os anos de 2008 e 2014, que auxiliaram na implementação da política de Avaliação Institucional Participativa, bem como coordenavam a aplicação das avaliações externas e a socialização de seus resultados.

\footnotetext{
4 A Resolução 05/2008 estabelece que cada CPA deve contar com representante dos diferentes segmentos da comunidade escolar (gestão, docentes, funcionários, estudantes e famílias). Os professores são remunerados por meio de horas-projeto. Já os funcionários, participam das reuniões da CPA dentro de sua jornada de trabalho. Cada Comissão possui uma organização quanto aos horários e a periodicidade dos encontros.

${ }^{5}$ Possuíam cargos efetivos na RMEC e entre os anos mencionados desempenharam a função de Assessoria da AIP. Antes de realizarmos as entrevistas, os membros da Assessoria de AIP assinaram o Termo de Consentimento e Livre Esclarecimento (TCLE).
} 
Consideramos, ainda, os dados obtidos com a análise dos materiais produzidos pelas escolas para a Reunião de Negociação ${ }^{6}$ de 2014.

A partir do enfoque descritivo-analítico (GIL, 2008), acompanhamos as escolas selecionadas por cerca de dez meses, registrando as observações em diário de campo, a fim de compreender os processos de avaliação institucional desenvolvidos. Após esse período e atentos a presença (ou não) de alguns dos elementos que foram considerados pilares da AIP em pesquisa desenvolvida pelo LOED (Laboratório de Observações e Estudos Descritivos) em $2013^{7}$, caracterizamos as escolas selecionadas da seguinte forma:

Quadro 1: Caracterização dos processos de AIP das escolas selecionadas.

\begin{tabular}{|c|c|}
\hline Escola & Processo de AIP \\
\hline $\begin{array}{l}\text { Escola Sueli } \\
\text { Carneiro e } \\
\text { Escola Nísia } \\
\text { Floresta } \\
\text { Augusta }^{(a)}\end{array}$ & $\begin{array}{l}\text { Frágil: pouca representatividade e/ou participação dos segmentos } \\
\text { escolares, reuniões sem frequência regular ou sem um tempo espaço } \\
\text { específico para a CPA. Debates esporádicos sobre aspectos pedagógicas } \\
\text { e sobre as demandas internas e externas à escola para o } \\
\text { compartilhamento das responsabilidades. }\end{array}$ \\
\hline $\begin{array}{l}\text { Escola Maria } \\
\text { Firmina dos } \\
\text { Reis }\end{array}$ & $\begin{array}{l}\text { Transitório: movimento de revitalização da CPA, com o chamamento } \\
\text { dos segmentos para sua composição. Calendário regular de reuniões. } \\
\text { Algumas discussões versavam sobre aspectos pedagógicos e } \\
\text { levantamento de demandas internas e externas à escola. }\end{array}$ \\
\hline $\begin{array}{l}\text { Escola Maria } \\
\text { Amélia de } \\
\text { Queiroz }\end{array}$ & $\begin{array}{l}\text { Potencializado: encontros quinzenais que, em sua maioria, contaram } \\
\text { com participação dos diferentes segmentos da comunidade escolar na } \\
\text { discussão sobre diversos assuntos, inclusive sobre projetos e ações } \\
\text { desenvolvidas pela escola, além de levantamento de demandas internas } \\
\text { e externas à instituição. }\end{array}$ \\
\hline
\end{tabular}

Fonte: Elaborado pela autora.

(a) Atribuímos nomes fictícios às escolas para atender aos preceitos éticos da pesquisa cientifica.

Entrevistamos os Orientadores Pedagógicos e professores dos $2^{\text {os }}, 5^{\text {os }}$ e $9^{\text {os }}$ anos de cada escola selecionada 8 . Os OPs foram entrevistados por serem os articuladores da CPA, conforme estabelecido na Resolução 05/2008. As escolas Nísia Floresta Augusta e Maria Amélia de Queiroz possuíam dois OPs cada e as demais apenas um Orientador Pedagógico. Já os docentes, escolhemos aqueles que atuavam nos anos escolares avaliados pela Provinha e

\footnotetext{
${ }^{6}$ Essas reuniões estão entre as ações da política de AIP da RMEC. São momentos de negociação de ações entre CPAs e o poder público, a partir das demandas apresentadas pelas escolas, em um processo de compartilhamento de responsabilidades.

${ }^{7}$ Entre esses elementos estão: composição da CPA e o calendário de suas reuniões; existência do OP como articulador da CPA; histórico da AIP na escola; presença de assuntos pedagógicos nos trabalhos desenvolvidos pela CPA; relação dos problemas identificados com a aprendizagem dos estudantes; levantamento de demandas à SME e à escola; cultura de avaliação pautada na participação dos diferentes atores escolares.

8 Antes de realizarmos as entrevistas, os OPs e professores assinaram o Termo de Consentimento e Livre Esclarecimento (TCLE). Vale dizer que o projeto de pesquisa foi submetido ao Comitê de Ética e aprovado em julho de 2015. Certificado de Apresentação de Apreciação Ética: 44673915.0.0000.5404.
} 
Prova Brasil. Quando havia mais de um professor desses anos escolares na escola, a entrevista foi realizada com o docente com mais anos de trabalho na instituição por entendermos que este, sua fala, poderia trazer maiores elementos sobre a escola que contribuiriam para a compreensão daquele contexto.

Nesse processo, fizemos uso da entrevista semiestruturada por proporcionar um "amplo campo de interrogativas, fruto de novas hipóteses que vão surgindo à medida que recebem as respostas do informante" (TRIVIÑOS, 1987, p. 127). Depois de transcritas, as entrevistas foram submetidas à análise de conteúdo em que as comunicações são analisadas a partir de procedimentos sistemáticos, de modo a descrever o conteúdo das mensagens (BARDIN, 1977).

Queremos destacar que uma das questões de nosso roteiro de entrevista buscava compreender se, na visão do entrevistado, a qualidade do trabalho realizado pela escola poderia ser conhecida pelos resultados obtidos nas avaliações externas ${ }^{9}$. As respostas a essa pergunta constituem os dados que serão apresentados e analisados a seguir. No entanto, ao realizarmos a análise de conteúdo, consideramos, também, as respostas dadas a outras questões que, porventura, traziam a relação entre qualidade e avaliação externa em larga escala.

\section{Qualidade e avaliação externa em larga escala nas vozes de OPs e professores}

Inicialmente apresentaremos o que foi dito por OPs e professores das escolas em que, no momento de desenvolvimento da pesquisa, seus processos de AIP estavam fragilizados. Como podemos observar nas falas apresentadas a seguir, para esses OPs e docentes, a avaliação externa em larga escala não traduz, integralmente, a qualidade do trabalho desenvolvido pela instituição. Boa parte desses entrevistados justifica suas afirmações a partir das características das avaliações, sobretudo quanto aos limites dos seus instrumentos, por exemplo: centralidade em determinadas áreas de conhecimento e do currículo nacional; composto por, apenas, questões escritas (não contemplando a oralidade); único para todo o País, sem dar conta das diferenças regionais; realizado em apenas um dia; não considera as especificidades dos estudantes com deficiência; abarca, em seus resultados, os alunos faltosos e/ou evadidos.

\footnotetext{
${ }^{9}$ Pergunta: A qualidade do trabalho realizado por esta escola pode ser conhecida pelos resultados obtidos nas avaliações externas? Por quê?
} 
Revista Educação e Políticas em Debate - v. 9, n. 2, p. 373 - 390, mai./ago. 2020 - ISSN 2238-8346

Quadro 2: Qualidade e avaliação externa em larga escala para OPs e docentes das escolas Sueli Carneiro e Nísia Floresta Augusta.

\begin{tabular}{|c|c|}
\hline & Escola Sueli Carneiro \\
\hline $\mathrm{OP}$ & $\begin{array}{l}\text { Ele espelha. Em alguns aspectos, né? Não são em todos. Por exemplo, a Provinha Brasil, é na leitura, } \\
\text { né? […] E eu acho que a prefeitura pode ter um olhar daquela escola e pode até trazer para nós } \\
\text { algumas coisas, um subsídio ou alguma formação que ele viu e que, às vezes, a escola, né? Porque é } \\
\text { diferente o olhar do OP, é diferente o olhar do professor, é diferente o olhar do vice, do diretor, né? [...] } \\
\text { e eu posso não ter visto porque a gente está tão envolvido no dia-a-dia ali... }\end{array}$ \\
\hline $\begin{array}{l}\text { Prof. } \\
2^{\mathrm{o}} \text { ano }\end{array}$ & $\begin{array}{l}\text { De certa forma, uma parte sim outra parte não. Eu acredito que cada ano, eu acho que se diferencia } \\
\text { o trabalho, devido a turma, devido ao professor, devido aos processos em si que vão acontecendo ao } \\
\text { longo daquele ano, então acho que uma parte traduz o ensino daquela escola, mas outra não, né? } \\
\text { [...] o ano que o professor conseguiu trabalhar de maneira mais tranquila com aqueles determinados } \\
\text { conteúdos que são tratados nos descritores e tal, eu acredito que sim. Mas tem ano que não dá para } \\
\text { ser fiel ao que acontece na escola [...] Então, depende eu acho muito do professor, do trabalho que é } \\
\text { realizado ao longo daquele ano. Então, eu acho que 50\% sim, mas o outro restante, não. }\end{array}$ \\
\hline $\begin{array}{l}\text { Prof. } \\
5^{\circ} \text { ano }\end{array}$ & $\begin{array}{l}\text { [...] vejo que não porque na realidade assim, a Prova Brasil é para que atinja um maior número, né? De } \\
\text { estados e as diferenças regionais são muito grandes, então alguma coisa sempre escapa dessa avaliação. }\end{array}$ \\
\hline $\begin{array}{l}\text { Prof. } \\
9^{\circ} \text { ano }\end{array}$ & $\begin{array}{l}\text { Ele pode ser conhecido, mas uma porcentagem minima do trabalho, né? Porque você pega, por } \\
\text { exemplo, a nossa escola o trabalho que a gente desenvolve aqui, eu acho que somente uma pessoa } \\
\text { ou um pesquisador, uma pessoa que esteja muito envolvida com a nossa comunidade vai ver os } \\
\text { nossos resultados porque o resultado da educação, ele não é de curto prazo, né? Faz hoje e saiu } \\
\text { amanhã. Qualquer resultado na educação é um resultado de longo prazo [...]. }\end{array}$ \\
\hline & Escola Nísia Floresta Augusta \\
\hline OP 1 & $\begin{array}{l}\text { Eu acho que uma escola se destaca por um conjunto de coisas, né? Professores que estão lá mais } \\
\text { tempo, a família... a presença da família nessa escola, questão financeira, questão de } \\
\text { localização, às vezes, influência, né? [...] então, assim, por que que a escola teve um bom } \\
\text { resultado? Porque ela faz uma série de coisas que envolve família, que envolve os alunos fora } \\
\text { do horário de aula, né? Tem uma série de projetos bacanas, né? O [Programa] Mais Educação } \\
\text { era um projeto que ajudou muito as escolas de Campinas, né? Na questão da alfabetização, isso } \\
\text { melhorou muito, muito os resultados, então isso acabou refletindo nos resultados dessas } \\
\text { avaliações. Então, assim, eu não percebo a escola só porque ela foi bem numa avaliação externa, } \\
\text { ela é boa porque foi bem numa Prova Brasil, por exemplo. Ela é boa por um conjunto de coisas, } \\
\text { ela tem um bom resultado nessa prova por uma série de questões envolvidas aí, né? }\end{array}$ \\
\hline $\mathrm{OP} 2$ & $\begin{array}{l}\text { Em relação ao currículo, né? Ao currículo proposto nacionalmente ou comumente, sabe? Então, } \\
\text { aí você vai olhar assim: Esse é o currículo, na escola, aconteceu isso, quando nós avaliamos o } \\
\text { resultado da escola aconteceu isso. Então, significa que aqui a escola não está dando conta, mas } \\
\text { não está dando conta do currículo, mas tem outra aprendizagem que não está sendo avaliada. }\end{array}$ \\
\hline $\begin{array}{c}\text { Prof. } \\
2^{\circ} \text { ano }\end{array}$ & $\begin{array}{l}\text { Olha, eu acho assim, 100\% não, sabe? Eu acho que depende o número, como é feito esse processo depois, } \\
\text { né? Tem alunos faltosos, evadidos, né? Que entram tudo nesse percentual aí no final do resultado. } \\
\text { Então, eu acho que deveria ser feito de acordo com a realidade de que os alunos prestaram, né? Então } \\
\text { tem essa parte aí que eu acho que deixa um pouquinho o nível baixo, lá embaixo. }\end{array}$ \\
\hline $\begin{array}{l}\text { Prof. } \\
5^{\circ} \text { ano }\end{array}$ & $\begin{array}{l}\text { Nossa, eu acho difícil. Porque é um dia marcado e nem sempre aquele dia a criança está bem, } \\
\text { tem o caso de criança com deficiência que não vem especializado para eles. Então, eu acho que } \\
\text { nem tanto, poderia ser melhor, eu acho. }\end{array}$ \\
\hline $\begin{array}{l}\text { Prof. } \\
9^{\circ} \text { ano }\end{array}$ & $\begin{array}{l}\text { Eu não creio que a avaliação externa ela demonstre integralmente o resultado da escola, não creio } \\
\text { que ela chegue a esse ponto. Da mesma forma como uma avaliação nossa comum, mensal, também } \\
\text { não vai exemplificar que o aluno é aquilo que tirou naquela prova. Então, tem que ter outros fatores } \\
\text { para que realmente seja analisado o desempenho de uma escola [..] Por exemplo, talvez uma } \\
\text { avaliação oral, não ser só escrita, ser oral. Alguém observar o desempenho e desenvolvimento da } \\
\text { escola em si, né? E ter alguém fiscalizando, olhando, observando como que éo dia-a-dia, como é que } \\
\text { é o comportamento dos alunos, como que é o desenvolvimento, como é que o interesse dos alunos. } \\
\text { Então, quer dizer, é muito mais complexo do que só uma avaliação escrita. }\end{array}$ \\
\hline
\end{tabular}

Fonte: elaborado pela autora. 
Parece-nos, assim, que para esses entrevistados, se fossem solucionadas as fragilidades do instrumento, a qualidade do trabalho desenvolvido pela escola poderia ser melhor revelada pelas avaliações externas em larga escala. Quase não há menção quanto aos aspectos externos à instituição e/ou práticas desenvolvidas que potencializam o processo formativo dos estudantes e que poderiam indicar aproximações com a concepção de qualidade social da instituição (SILVA, 2009).

Para suprir os limites apresentados, um dos professores propõe a observação do dia-adia da escola e destaca que é preciso considerar o interesse dos alunos. Não são mencionadas as condições de trabalho e as políticas públicas (in)existentes ou, ainda, fatores relacionados ao contexto econômico e social. Assim, entendemos que esse docente atribui maior peso ao comportamento do estudante ao abordar a qualidade do trabalho realizado pela escola. Chamou-nos atenção, ainda, a fala de uma professora quanto ao trabalho em sala de aula a partir dos descritores das avaliações externas em larga escala. Para ela, a qualidade está associada ao trabalho do professor naquele ano e o quanto conseguiu abordar, com sua turma, tais descritores. Nessa perspectiva, a qualidade aparece quando as metas são alcançadas e, para tanto, é necessário seguir a "cartilha” das avaliações externas que, por sua vez, como sinalizado por Menegão (2016), pode conduzir a um estreitamento curricular, já que o ensino passa a ser guiado pela matriz dessas avaliações. Em ambas as falas, percebemos que a qualidade da escola está mais associada aos sujeitos pedagógicos (estudantes e docentes) do que aos sujeitos políticos (PACHECO, 2014). Por conseguinte, nessa perspectiva, ajustar as ações dos sujeitos pedagógicos - comportamento do estudante e o trabalho do docente em sala de aula - pode favorecer a qualidade institucional.

Embora não seja maioria, não podemos deixar de ouvir as vozes que trazem outra melodia neste debate. Uma OP, ao falar sobre qualidade, destacou a permanência dos professores na mesma escola, o envolvimento das famílias, as questões relacionadas ao entorno e seu nível socioeconômico e os projetos desenvolvidos pela instituição. Como dito pela entrevistada, a escola "é boa por um conjunto de coisas" que, para ela, acabam aparecendo nos resultados obtidos nas avaliações externas ("ela tem um bom resultado nessa prova por uma série de questões envolvidas aî”). Outra OP destaca que a escola proporciona aprendizagens aos estudantes que vão além daquelas previstas no currículo oficial. E, para um dos professores, é necessário acompanhar a vida escolar, pois os resultados da educação são a longo prazo, o que nos faz entender que, em sua visão, é preciso considerar a educação enquanto processo com frutos que não aparecem nos resultados imediatos e quantificáveis das avaliações externas, mas na atuação futura do estudante. 
Vale lembrar que, com apresentado anteriormente, consideramos que os processos de AIP desenvolvidos por essas escolas estavam fragilizados. Assim, embora haja uma diversidade de posicionamentos quanto à relação entre qualidade e avaliação externa em larga escala, nos encontros das CPAs não presenciamos debates sobre a temática, de modo a promover reflexões sobre políticas educacionais, currículo e avaliação, por exemplo. De modo geral, as discussões versavam sobre a infraestrutura da escola, a (in)existência de materiais e a realização de alguns projetos e eventos. Na Escola Nísia Floresta, o tema até apareceu em algumas reuniões da CPA. No entanto, é importante dizer que por um tempo essas reuniões ocorreram durante o Trabalho Docente Coletivo ${ }^{10}$. Desse modo, mesmo com a presença de alguns representantes dos segmentos da comunidade escolar nesses encontros, não houve a articulação entre os diferentes olhares quanto à temática debatida. As discussões foram protagonizadas pelos docentes e gestores que, algumas vezes, mencionaram sobre a realização de atividades nos moldes das avaliações externas em larga escala. Notamos, portanto, que "apesar de desconfiarem da capacidade desses exames refletir a qualidade de ensino ou impulsionar a melhoria da educação, os docentes não ficam indiferentes aos seus resultados" (SCHNEIDER, 2013, p. 27) e acabam por realizar atividades alinhadas aos testes padronizados.

Na Escola Maria Firmina dos Reis, onde os processos de AIP estavam sendo revitalizados, percebemos que a OP e professores entrevistados, assim como os Orientadores Pedagógicos e docentes das escolas Sueli Carneiro e Nísia Floresta Augusta, acreditam que as avaliações externas em larga escala não espelham, totalmente, a qualidade do trabalho desenvolvido pela escola. Houve destaque para os limites dos instrumentos que compõem as avaliações externas, como o foco em alguns conteúdos/habilidades. No entanto, notamos, também, certa preocupação com a contextualização dos resultados. Assim, para além dos apontamentos relacionados ao instrumento, as avaliações externas em larga escala não traduzem toda a qualidade do trabalho desenvolvido pela instituição porque não ocorre um acompanhamento constante do cotidiano da escola e das ações desenvolvidas.

${ }^{10}$ Reunião que compõe a carga horária de trabalho semanal dos docentes e gestores. 
Revista Educação e Políticas em Debate - v. 9, n. 2, p. 373 - 390, mai./ago. 2020 - ISSN 2238-8346

Quadro 3: Qualidade e avaliação externa em larga escala para OPs e docentes da Escola Maria Firmina dos Reis

\begin{tabular}{|c|c|}
\hline & Reis \\
\hline $\mathrm{OP}$ & $\begin{array}{l}\text { Quando eu penso, por exemplo, na Provinha Brasil, ela só avalia a leitura. Então, eu acho } \\
\text { que é uma avaliação um pouco equivocada, né? Ela poderia ser uma avaliação planejada } \\
\text { de uma forma um pouco mais ampla, onde eu possa olhar para aquilo e saber realmente } \\
\text { qual é o conhecimento que essa criança traz. [...] a questão da prova ser } \\
\text { descontextualizada, é resultado pelo resultado em si, né? [...] A gente tem muitas coisas } \\
\text { que acontecem no cotidiano que esses alunos trazem para cá que não são contextualizados } \\
\text { nos resultados. Então, eu acho que não, eu acho que esse resultado é muito cru, muito frio. } \\
\text { [...] Eu acho que se a CPA enquanto comissão já problematizasse isso, contextualizasse, } \\
\text { ampliasse essa discussão para comunidade, já ajudaria bastante, né? Porque uma coisa é } \\
\text { você ter os resultados do processo ensino-aprendizagem lá engavetado e outra coisa é vocêe } \\
\text { trazer para o contexto, para o cotidiano escolar, para as discussões. Eu acho que colocar as } \\
\text { pessoas para pensarem sobre, isso já ajuda bastante. }\end{array}$ \\
\hline $\begin{array}{l}\text { Prof. } \\
2^{\circ} \text { ano }\end{array}$ & $\begin{array}{l}\text { Porque eu acho que existem outras habilidades e outros conteúdos, outras habilidades que } \\
\text { são trabalhadas e que não existe espaço ali para elas serem... para aparecerem, né? Por } \\
\text { exemplo, a qualidade de uma produção de texto, por exemplo, né? Numa prova, mesmo } \\
\text { que eles estejam no } 2^{\circ} \text { ano, eles já produzem textos e não existe espaço para isso, que aqui é } \\
\text { uma coisa que a gente trabalha muito nessa questão. Então, eu não acho que só essa } \\
\text { avaliação externa possa transparecer todo o trabalho que é feito aqui, acredito que não. }\end{array}$ \\
\hline $\begin{array}{l}\text { Prof. } \\
5^{\circ} \text { ano }\end{array}$ & $\begin{array}{l}\text { [...] eu não acho que a Prova Brasil e nenhuma prova institucional } l^{(a)} \text { seja fielmente... ela } \\
\text { retrate fielmente o trabalho da escola, não acho isso. [...] Porque eles não estão aqui todo } \\
\text { dia, né? [...] A professora preparada uma prova porque ela sabe o que que é que ela deu, } \\
\text { até onde ela conseguiu chegar. Eu não vou dar uma prova para os meus alunos para } \\
\text { provar que eles não sabem. Eu quero que tudo que eu dei, eles sejam capazes de fazer sobre } \\
\text { um determinado tempo, que eles tenham autonomia para fazer [...] Agora, a prova } \\
\text { institucional ela não vê isso dos meus alunos. Eles veem o que é que a professora tinha que } \\
\text { ter dado e não o que a professora conseguiu dar, acho que é isso. }\end{array}$ \\
\hline $\begin{array}{c}\text { Prof. } \\
9^{\circ} \text { ano }\end{array}$ & $\begin{array}{l}\text { Eu acho que avaliação externa é importante sim porque, de qualquer maneira, avalia e } \\
\text { observa como tem ocorrido a aprendizagem, eu só não acho que ela dê conta de avaliar de } \\
\text { uma forma ampla, né? Totalmente competente, mas eu acho que não deixa de ser importante. } \\
\text { [...] Porque o dia-a-dia da escola é muito mais rico do que uma avaliação. A gente sabe } \\
\text { disso, a gente sabe que muitas coisas que acontecem, uma avaliação não vai medir, mas } \\
\text { também não tem como você falar em nível nacional, né? Um país tão grande, como que vocêe } \\
\text { faria diferente se não fosse uma prova desse tipo. [...] na penúltima avaliação externa, os } \\
\text { alunos não tiveram um bom desempenho. A escola não obteve um bom indice porque os } \\
\text { alunos, em uma atitude de rebeldia, resolveram boicotar a prova. Então, essa avaliação não } \\
\text { conseguiu medir aquilo que eles sabiam porque, na verdade, eles não fizeram mostrando } \\
\text { aquilo que eles sabiam ou não. [...] E acho que tem a questão da avaliação para o aluno, que } \\
\text { o aluno gosta de um resultado meio que imediato, né? E, assim, ele fazer uma avaliação que, } \\
\text { para ele, não tem uma nota, que não vai ter muita utilidade, entre aspas, ele não entende que } \\
\text { isso vai avaliar a escola e que isso vai indicar a forma como a escola vai trabalhar ou não, é } \\
\text { muito abstrato, para o aluno, é muito abstrato. }\end{array}$ \\
\hline
\end{tabular}

Fonte: Elaborado pela autora.

(a) A professora se refere à avaliação externa em larga escala.

Desse modo, entendemos que, para a maioria desses entrevistados, a qualidade do trabalho realizado pela escola não é integralmente revelada pelas avaliações externas em 
larga escala devido à falta de contextualização de seus resultados, sobretudo quanto ao acompanhamento do cotidiano escolar e das ações desenvolvidas. Embora concordemos que os resultados das avaliações externas precisam ser contextualizados, nos perguntamos: a quem cabe realizar tal contextualização? Esse não seria um movimento de reflexão a ser desenvolvido pela CPA - com representantes dos diferentes segmentos que vivenciam a escola - em um processo de articulação entre múltiplos aspectos da realidade institucional?

As falas apresentadas nos indicam que apesar de considerarem que não é possível conhecer integralmente a qualidade da escola pelos índices quantitativos obtidos em testes padronizados, ainda não há uma análise ampliada, na perspectiva da qualidade social, que posicione esses dados naquele contexto, de modo a demonstrar suas aproximações e/ou distanciamentos quanto a sua realidade e os propósitos formativos da instituição. Nessa direção, a OP afirma que "se a CPA enquanto comissão já problematizasse isso, contextualizasse, ampliasse essa discussão para comunidade, já ajudaria bastante”. Assim como ela, acreditamos que cabe a Comissão Própria de Avaliação promover esses debates, uma vez que conforme previsto na Resolução 05/2008, a CPA tem como função organizar e estudar os diversos dados relacionados à instituição, identificando potencialidades e vulnerabilidades.

Ainda a partir das vozes ouvidas na Escola Maria Firmina dos Reis, queremos chamar atenção para o que foi dito por uma das professoras. Durante a entrevista, a docente mencionou que a escola não obteve bom resultado em uma das avaliações externas porque os estudantes tiveram um ato de rebeldia e boicotaram a avaliação. Para a professora, os alunos não fizeram a prova mostrando o que sabiam e ressaltou que essas avaliações não possuem significado para eles, uma vez que não geram uma nota. De acordo com a entrevistada, o estudante "não entende que isso vai avaliar a escola e que isso vai indicar a forma como a escola vai trabalhar".

A fala dessa professora nos proporciona várias reflexões. Em primeiro lugar, retomamos o que mencionamos anteriormente: o estudo e a contextualização dessas avaliações, a partir dos olhares da CPA, ainda não ocorre. Em segundo lugar, e como decorrência do primeiro, a ausência de um movimento de autoavaliação que considere esses dados, para a sua contextualização, repercute na relação entre os estudantes e essas avaliações. Conhecendo-as apenas como uma prova pontual, sem serem envolvidos em processos de discussão sobre elas, os alunos não entendem seus propósitos e porquê elas existem. Em último lugar, quando afirma que as avaliações externas indicam a forma como a escola vai trabalhar, a docente sinaliza que ações são desenvolvidas a partir dessas avaliações, o que nos leva a pensar sobre a realização de atividades em consonância com o que é 
estabelecido nas avaliações externas em larga escala, como já sinalizados pela literatura da área (RAVITCH, 2013; SCHNEIDER, 2013; MENEGÃO, 2016).

As colocações dessa professora, por exemplo, poderiam permear as discussões da CPA, de modo a problematizar os significados que os diferentes segmentos atribuem às avaliações externas que, por sua vez, podem repercutir nas ações realizadas. Será que essas ações favorecem a qualidade da instituição? E, principalmente, qual qualidade estão buscando? Nos encontros da CPA da Escola Maria Firmina dos Reis, quando as avaliações externas foram pautadas, observamos que houve um enfoque nos seus instrumentos e resultados, com a proposição de ações que almejavam o aumento dos índices obtidos (aplicação de provão, por exemplo). Assim, percebemos que, em certos momentos, a avaliação externa configurou a avaliação interna, já que esta ficou direcionada para aquela, "contribuindo para a sobreposição da qualidade-desempenho face à qualidade-melhoria” (PACHECO, 2014, p. 369).

Por fim, temos as vozes dos OPs e professores da Escola Maria Amélia de Queiroz, com processos mais potencializados de AIP. Para esses entrevistados, assim como para os demais, as avaliações externas em larga escala não traduzem, de modo integral, o trabalho desenvolvido pela escola. Foram lembrados os fatores que podem interferir nos resultados, bem como a importância do contexto escolar. 
Revista Educação e Políticas em Debate - v. 9, n. 2, p. 373 - 390, mai./ago. 2020 - ISSN 2238-8346

Quadro 4: Qualidade e avaliação externa em larga escala para OPs e docentes da Escola Maria Amélia de Queiroz

\begin{tabular}{|c|c|}
\hline & Escola Maria Amélia de Queiroz \\
\hline $\mathrm{OP} 1$ & $\begin{array}{l}\text { Acho que um pouco, talvez, mas pouco, não dá para dizer acho que se a escola foi mal em termos de } \\
\text { Prova Brasil, se o Ideb é ruim, não dá para dizer que o trabalho aqui é ruim, eu acho que não, } \\
\text { acho até que é perigoso [...] Então, durante muito tempo, eu não atribui importância nenhuma, a } \\
\text { bem da verdade, eu achava até, uma coisa de preconceito mesmo, "ah não, é avaliação externa. Não } \\
\text { estou nem aí para ela". Hoje eu já penso diferente, eu acho que é um dado, eu acho que é um dado. } \\
\text { A importância assim, é mais um dado, que eu acho que tem que ser olhado, né? Acho que é } \\
\text { interessante a gente conhecer... [...] Eu acho que com o dado assim, não dá para ser ignorado, hoje } \\
\text { eu já não penso, num determinado momento eu ignorava solenemente, nem estava aí. Acho que } \\
\text { agora não dá mais para ser ignorado e também não dá para ser endeusado, né? Vamos trabalhar } \\
\text { para melhorar nosso Ideb! Não, vamos trabalhar para melhorar para trabalhar a qualidade do } \\
\text { ensino que a gente oferece para as crianças, os alunos daqui, né? Tá? Acho que é isso. }\end{array}$ \\
\hline $\mathrm{OP} 2$ & 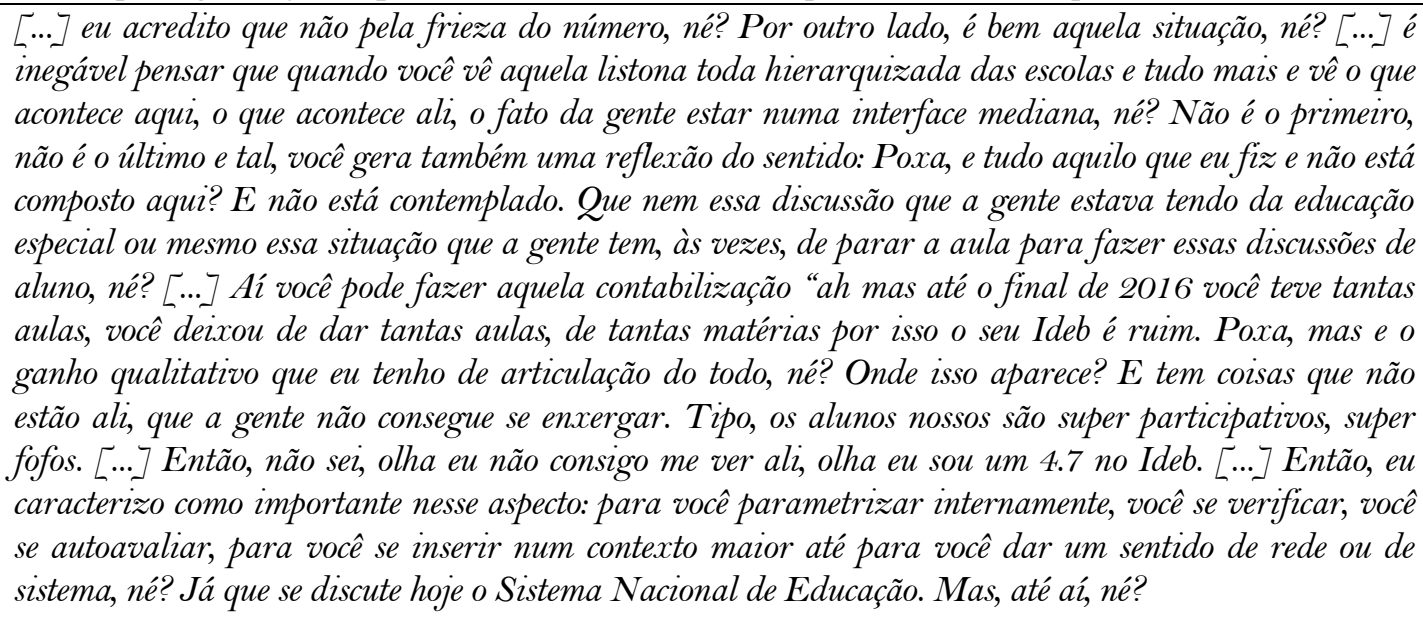 \\
\hline & $\begin{array}{l}\text { É, ela pode dar uma visibilidade, mas não que a qualidade do trabalho seja revelada, né? [...] vamos supor } \\
\text { que vai que aquela prova caiu um projeto, naquela prova caiu uma temática que seja um projeto que a } \\
\text { escola tenha trabalhado, então, vai revelar que ela trabalhou aquele tema, mas, às vezes, não revela o todo } \\
\text { do trabalho [...] É, eu não acredito que ela vá traduzir, mas ela dá indícios, acho que ela dá indícios. [...].] } \\
\text { eu acho que o tempo de permanência do professor na escola, né? De conhecer a comunidade, a formação do } \\
\text { professor, da equipe, eu acho que o trabalho coletivo acontecendo de fato que vai influenciar essa qualidade, } \\
\text { né? Porque só a avaliação em si, ela não vai mudar a prática da escola, do professor. }\end{array}$ \\
\hline $\begin{array}{l}\text { Prof. } 5^{\circ} \\
\text { ano }\end{array}$ & $\begin{array}{l}\text { Porque o trabalho da escola vai muito além da prova, né? Primeiro que uma avaliação não mostra o } \\
\text { que uma criança sabe, né? [...] ela mostra muito pouco porque tem ' } n \text { ' fatores que influenciam no } \\
\text { resultado de uma avaliação. O que ele já teve acesso, o que ele não teve acesso, o momento que ele estava } \\
\text { naquele dia, a forma que foi escrita, a forma do papel, a forma de aplicação, o tempo de aplicação... } \\
\text { Então, eu acho que tem muita coisa que influencia numa avaliação externa. […] acho que ela pode } \\
\text { trazer alguns indícios, não digo que ela é inútil, não acho que ela é inútil, mas acho que ela apresenta } \\
\text { alguns primeiros indícios, mas acho que precisa ser uma avaliação muito mais completa. }\end{array}$ \\
\hline $\begin{array}{c}\text { Prof. } 9^{\circ} \\
\text { ano }\end{array}$ & $\begin{array}{l}\text { Se tivesse comprometimento dos alunos, sim. Mas quando não tem, eu acho que não, não totalmente. Se } \\
\text { pudesse fazer assim: ah, vamos pegar } 5 \text { alunos comprometidos e } 5 \text { não comprometidos para ter uma média. } \\
\text { Se fizesse só com esses } 10 \text { alunos, por exemplo, talvez teríamos um meio termo com relação ao trabalho } \\
\text { efetuado nesse perído, mas como eu acho que, muitas vezes, a quantidade de alunos não compromissados é } \\
\text { maior do que os compromissados, dá uma defasagem maior. [...] a visão que eu tenho é que, muitas vezes, } \\
\text { por não ser prova do professor, não tem um certo, um grau de compromisso adequado com os alunos, né? Ȧs } \\
\text { vezes, o aluno "ah, não vale nota", tem essa percepção de que não vale nota. Então, faz de qualquer jeito } \\
\text { esse tipo de avaliação. [...] Às vezes, a defasagem do conhecimento dos anos, nem sempre o que é previsto } \\
\text { para o aluno do } 6 \text { o ano aprender, não se cumpre [...]. Então, essa defasagem muitas vezes acaba } \\
\text { comprometendo também o resultado de uma prova externa. }\end{array}$ \\
\hline
\end{tabular}

Fonte: Elaborado pela autora. 
Como podemos notar, alguns docentes mencionaram fatores que interferem nos resultados das avaliações externas em larga escala, por exemplo, a aproximação entre o que a prova aborda e o que foi trabalhado em sala com os estudantes, o instrumento e a forma como ocorre sua aplicação e a defasagem de conteúdos. Um deles ressaltou, também, o comprometimento dos alunos (ou a sua falta). Para esse professor, por não valer nota, o estudante faz a prova "de qualquer jeito" ${ }^{11}$. Nesse sentido, essas vozes se aproximam daquelas que encontramos nas demais escolas e nos soam como “justificativa” para os índices obtidos.

No entanto, associado aos fatores que podem interferir nos resultados, duas docentes trazem outros apontamentos. Uma delas menciona que o trabalho desenvolvido pela escola vai além da prova, o que nos faz entender que, para ela, nem tudo que é realizado pela instituição, e que se relaciona a sua qualidade, aparecerá em um teste. A outra professora destaca o tempo de atuação do professor na escola, bem como sua formação, o conhecimento da comunidade e o trabalho coletivo. Nesse sentido, podemos dizer que a qualidade da escola, para essa docente, não se limita aos índices obtidos nas avaliações externas em larga escala e, portanto, contempla os elementos citados.

De modo semelhante, temos as falas dos OPs. Um deles enfatiza que o trabalho da escola deve estar a serviço do ensino oferecido aos alunos e não se voltar para o aumento do Ideb. Parece-nos, assim, que em seu entendimento, a qualidade do trabalho desenvolvido pela instituição aproxima-se mais daquilo que ela proporciona aos estudantes - e esse deve ser o seu foco - do que dos resultados das avaliações externas. Para o outro OP, as avaliações externas trazem números frios que não apreendem os processos vivenciados pela escola, como as discussões coletivas e a participação dos estudantes. Por isso, ele atribui à avaliação externa a importância de contribuir com a autoavaliação da instituição.

No entanto, considerando os depoimentos apresentados, entendemos que a autoavaliação abarcando a avaliação externa pode ser um movimento incipiente na escola. Isso porque tal relação só apareceu na fala de um dos entrevistados e porque um dos OPs afirmou que por muito tempo negou as avaliações externas e "não estava nem aí para ela" ${ }^{12}$. Durante o período que acompanhamos a escola, não presenciamos discussões sobre as avaliações externas em larga escala nas reuniões da CPA. Timidamente, o tema foi abordado quando, em um dos encontros, o Plano Municipal de Educação foi debatido. Ao apresentar a meta relacionada ao Ideb, a OP1 explicou que esse índice contempla o desempenho dos estudantes e o fluxo escolar.

11 Foge do escopo deste trabalho a relação dos estudantes com as avaliações externas em larga escala, entretanto, consideramos relevante realizar pesquisas nessa direção.

${ }^{12}$ Nessa análise considerando, também, que era o segundo ano de trabalho do $\mathrm{OP} 2$ na Escola Maria Amélia de Queiroz, enquanto o OP1 estava nessa escola há 9 anos. 
Concordamos com o $\mathrm{OP} 2$ da Escola Maria Amélia de Queiroz quanto à articulação entre avaliação externa e autoavaliação. Acreditamos que essa articulação pode acontecer nos encontros da CPA, com a participação, portanto, dos representantes da comunidade (gestores, docentes, discentes, funcionários e familiares). Na orquestração das múltiplas vozes na discussão sobre a qualidade da escola, diversos indicadores, dentre eles os dados das avaliações externas, precisam ser analisados, afinal, de certa forma, dizem sobre a escola. E, nesse processo, o debate sobre os diferentes posicionamentos pode contribuir para a construção coletiva sobre o que se entende por qualidade da escola e como buscá-la/aprimorá-la.

Como ressaltamos na primeira seção deste artigo, as avaliações externas em larga escala já fazem parte do cotidiano das escolas públicas brasileiras. Não há como negá-las, uma vez que, periodicamente, os estudantes são submetidos aos testes padronizados. E considerando que a partir desses resultados ocorre a (re)formulação de políticas públicas (COELHO, 2008; PACHECO, 2014), não podemos nos furtar dessa discussão ou, então, prevalecerá a concepção de qualidade “centrada em standards, [em] formas de governamentalidade curricular expressas nas práticas quotidianas da educação escolar, cada vez mais inseridas numa lógica empresarial para a educação”(PACHECO, 2014, p. 367).

Concordemos ou não com seus instrumentos e com a sua lógica, apenas nos apropriando dos aspectos políticos e técnicos das avaliações externas poderemos nos posicionar nesse campo de disputa, trazendo dados sobre a realidade objetiva das escolas e suas comunidades, em um processo de construção coletiva da qualidade socialmente referenciada e na "luta por financiamento adequado, pelo reconhecimento social e valorização dos trabalhadores em educação" (SILVA, 2009, p. 225).

\section{Para finalizar}

Neste artigo abordamos a relação entre qualidade e avaliação externa em larga escala a partir das vozes de Orientadores Pedagógicos e professores de quatro escolas da RMEC. A referida rede de ensino, como destacamos, possui uma política de Avaliação Institucional Participativa, cujo objetivo é fortalecer os processos de autoavaliação das escolas municipais na articulação dos diferentes olhares que compõem a comunidade escolar. A existência dessa política nos despertou interesse e nos fez querer entender se havia diferença nas relações entre qualidade e avaliação externa estabelecida por OPs e docentes de escolas com diferentes cenários indicativos de enraizamento da AIP.

Nas quatro escolas, os OPs e docentes entrevistados destacaram que o trabalho desenvolvido pela instituição não pode ser conhecido, exclusivamente, pelos resultados da 
avaliação externa em larga escala. Dito de outro modo, nenhum deles reduziu a qualidade da escola aos índices quantificáveis obtidos nessas avaliações. No entanto, percebemos que a maioria dos OPs e professores das escolas com processos frágeis de AIP salientaram, em suas respostas, as características das avaliações externas, sobretudo o limite dos instrumentos (centralizado em alguns conteúdos/habilidades, realizado em apenas um dia, etc.). Nas demais escolas, além das características das avaliações, boa parte dos entrevistados ressaltou o contexto na discussão sobre a qualidade da instituição. Algumas dessas respostas sinalizam outros elementos que devem ser observados, mas ainda não aprofundam as reflexões, compreendendo qualidade da escola de modo multidimensional.

Embora não tenha sido o nosso foco analisar detalhadamente como ocorrem debates sobre as avaliações externas em larga escala nos processos de autoavaliação, pelas respostas obtidas e pelas observações realizadas, percebemos que o tema, quando aparece nos encontros da CPA, caminha na direção de proposição de ações em consonância com as avaliações externas (como nas escolas Nísia Floresta Augusta e Maria Firmina dos Reis), ou tem sido abordado de forma incipiente na escola onde encontramos um movimento mais potencializado de Avaliação Institucional Participativa (Escola Maria Amélia de Queiroz).

Considerando a Resolução 05/2008, entendemos que a CPA poderia mediar os debates acerca das avaliações externas, de modo a problematizá-la, fazendo emergir reflexões que poderiam contribuir com a (des)construção de concepções sobre a qualidade da escola, uma vez que, como vimos, trata-se de um conceito que não é igualmente entendido por todos. Nesse processo, defendemos que o horizonte deve estar na qualidade social da educação, pois somente ela, por não ser refém dos "resultados estabelecidos a priori e [das] medidas lineares descontextualizadas" (SILVA, 2009, p. 223), está a serviço da formação humana e ampliada dos estudantes.

\section{Referências Bibliográficas}

BARDIN, Laurence. Análise de conteúdo. Lisboa, Portugal: Edição 70, 1977.

CABRITO, Belmiro Gil. Avaliar a qualidade em educação: avaliar o quê? Avaliar como? Avaliar para quê?. Cad. CEDES [online]. 2009, vol.29, n.78 [cited 2020-06-03], pp.178-200. Available from: $<$ http://www.scielo.br/scielo.php?script=sci arttext\&pid=S010132622009000200003\&lng=en\&nrm=iso $>$. ISSN 1678-7110>. DOI:

https://doi.org/10.1590/S0101-32622009000200003. 
COELHO, Maria Inês de Matos. Vinte anos de avaliação da educação básica no Brasil: aprendizagens e desafios. Ensaio: aval.pol.públ.Educ. [online]. 2008, vol.16, n.59, pp.229-258. ISSN 1809-4465. DOI: http://dx.doi.org/10.1590/S0104-40362008000200005. FREITAS, Luiz Carlos de. Caminhos da avaliação de sistemas educacionais no Brasil: o embate entre a cultura da auditoria e a cultura da avaliação In: BAUER, A.; GATTI, B. A. (Orgs.). Vinte e cinco anos de avaliação de sistemas educacionais no Brasil implicações nas redes de ensino, no currículo e na formação de professores. Florianópolis, SC: Insular, 2013.

GIL, A. C. Métodos e técnicas de pesquisa social. 6. ed. São Paulo: Atlas, 2008.

INEP. Saeb. Disponível em: < http://portal.inep.gov.br/web/saeb/aneb-e-anresc>. Acesso em: 7 jul. 2017.

LIBÂNEO, J. C. Internacionalização das políticas educacionais e repercussões no funcionamento curricular e pedagógico das escolas. In: LIBÂNEO, J. C.; SUANNO, M. V. R.; LIMONTA, S. V. (Org.). Qualidade da escola pública: políticas educacionais, didática e formação de professores. Goiânia: Ceped Publicações, 2013.

LOED - Laboratório de Observação e Estudos Descritivos. Avaliação institucional participativa como eixo estruturante de uma política de regulação da qualidade do ensino negociada com as escolas. Documento de Trabalho. Campinas, Universidade Estadual de Campinas, Faculdade de Educação, 2013.

MENEGÃO, Rita de Cássia Silva Godoi. Os impactos da avaliação em larga escala nos currículos escolares. Práxis Educativa, Ponta Grossa, PR, v. 11, n. 3, p. 641-656, Dez 2016. Available from $<$ https://www.revistas2.uepg.br/index.php/praxiseducativa/article/view/8995/5248>. ISSN 1809-4031. DOI: https://doi.org/10.5212/PraxEduc.v.11i3.0007.

OLIVEIRA, Romualdo Portela de; ARAUJO, Gilda Cardoso de. Qualidade do ensino: uma nova dimensão da luta pelo direito à educação. Rev. Bras. Educ., Rio de Janeiro, n. 28, p. 5-23, Apr. 2005. Available from $<$ http://www.scielo.br/scielo.php? script=sci arttext\&pid=S141324782005000100002\&lng=en\&nrm=iso $>$. ISSN 1809-449X. DOI:

https://doi.org/10.1590/S1413-24782005000100002.

PACHECO, José Augusto. Políticas de avaliação e qualidade da educação. Uma análise crítica no contexto da avaliação externa de escolas, em Portugal. Avaliação (Campinas) [online]. 2014, vol.19, n.2 [cited 2020-06-01], pp.363-371. Available

from: http://www.scielo.br/scielo.php?script=sci_arttext\&pid=S1414-

40772014000200005\&lng=en\&nrm=iso . ISSN 1414-4077.

DOI: http://dx.doi.org/10.1590/S1414-40772014000200005.

PEREIRA, Rodrigo Silva. A política de competências e habilidades na educação básica pública: relações entre Brasil e OCDE. Tese (Doutorado em Educação) - Faculdade de Educação, Universidade de Brasília, Brasília, 2016.

PREFEITURA MUNICIPAL DE CAMPINAS. Secretaria Municipal de Educação.

Resolução n. 05/2008, de 6 de maio de 2008. Estabelece as diretrizes para a implementação do processo de Avaliação Interna das Unidades Municipais de Ensino Fundamental e para a constituição da Comissão Própria de Avaliação. Campinas, 2008. 
RAVITCH, D. Reign of error: The hoax of the privatization movement and the danger to american's public schools. New York: Alfred A. Knopf, 2013.

ROBERTSON, Susan L. A estranha não morte da privatização neoliberal na Estratégia 2020 para a educação do Banco Mundial. Rev. Bras. Educ., Rio de Janeiro, v. 17, n. 50, p. 283-302, Aug. 2012. Available from: $<$ http://www.scielo.br/scielo.php? script=sci_arttext\&pid=S141324782012000200003\&lng=en\&nrm=iso $>$. ISSN 1413-2478 DOI: https://doi.org/10.1590/S1413-24782012000200003.

SCHNEIDER. Marilda Pasqual. Políticas de avaliação em larga escala e a construção de um currículo nacional para a educação básica. Rev. Cient., São Paulo, n. 30, p. 17-33, jan./abr. 2013. Available from <file:///C:/Users/HOME/Downloads/3537-23860-1-PB\%20(1).pdf>. ISSN 1517-1949. DOI: https://doi.org/10.5585/EccoS.n30.3537.

SILVA, Maria Abádia da. Qualidade social da educação pública: algumas aproximações. Cad. CEDES, Campinas, v. 29, n. 78, p. 216-226, Aug. 2009. Available from

$<$ http://www.scielo.br/scielo.php? script=sci arttext\&pid=S010132622009000200005\&lng=en\&nrm=iso $>$. ISSN 1678-7110. DOI:

https://doi.org/10.1590/S0101-32622009000200005.

SOUSA, Sandra Zákia. Concepções de qualidade da educação básica forjadas por meio de avaliações em larga escala. Avaliação (Campinas), Sorocaba, v. 19, n. 2, p. 407-420, July 2014. Available from $<$ http:/ / www.scielo.br/scielo.php? script=sci_arttext\&pid=S141440772014000200008\&lng=en\&nrm=iso $>$. ISSN 1414-4077. DOI: https://doi.org/10.1590/S1414-40772014000200008.

SOUSA, Sandra Maria Zákia Lian; LOPES, Valéria Virgínia. Avaliação nas políticas educacionais atuais reitera desigualdades. Revista ADUSP., São Paulo, SP, n. jan. 2010, 2010.

TRIVIÑOS, A. N. S. Introdução à pesquisa em Ciências Sociais: a pesquisa qualitativa em educação. São Paulo: Atlas, 1987. 